\title{
In-vivo Pharmacokinetic Study of Matrix Tablets of Atenolol Prepared by Sintering Technique
}

Chandan Mohanty $^{1 *}$, KV Subrahmanyam ${ }^{2}$

${ }^{1}$ Guru Nanak Institutions Technical Campus-School of pharmacy, Ibrahimpatnam, Hyderabad-501506, Telangana, India

${ }^{2}$ Siddhartha Institutions of Pharmacy, Narapally (V), Ghatkesar (M), Hyderabad-501506, Telangana, India

DOI: $10.36347 /$ sajp.2021.v10i04.003

| Received: 21.02.2021 | Accepted: 10.04.2021 | Published: 13.04.2021

*Corresponding author: Chandan Mohanty

Abstract

Original Research Article

The present study involved in-vivo pharmacokinetic evaluation of sintered matrix tablets of Atenolol in comparison to Atenolol pure drug and unsintered matrix tablets of Atenolol. The objective of the present investigation was to study the effect of sintering technique in development of controlled release dosage form. The Atenolol pure drug solution, both formulated unsintered and sintered controlled release matrix tablets of Atenolol were tested for in-vivo pharmacokinetic study in healthy male New Zealand rabbits $(n=3)$. The plasma concentrations of Atenolol drug were determined by a validated HPLC method. From the time versus plasma drug concentration data, various pharmacokinetic parameters $\left(\mathrm{C}_{\max }, \mathrm{T}_{\max }, \mathrm{AUC}, \mathrm{K}_{\mathrm{E}}\right.$ and $\left.\mathrm{t}_{1 / 2}\right)$ were estimated. $\mathrm{T}_{\max }$ for pure drug, unsintered and sintered tablets was found to be $2 \mathrm{~h}, 3 \mathrm{hr}$ and $4 \mathrm{~h}$ with $\mathrm{C}_{\max }$ values of $751.00 \pm 10.53 \mathrm{ng} / \mathrm{ml}, 639.33 \pm 10.40 \mathrm{ng} / \mathrm{ml}$ and $518.00 \pm$ $8.54 \mathrm{ng} / \mathrm{ml}$ respectively. Increase of $\mathrm{T}_{\max }$ values in sintered tablets as compared to the of pure drug and unsintered tablets suggested slow absorption of drug from the formulated sintered tablets and the availability of drug at a controlled manner. An increase of the elimination half- life $\left(\mathrm{T}_{1 / 2}\right)$ and decrease in elimination rate constant $\left(\mathrm{K}_{\mathrm{E}}\right)$ of drug in sintered matrix tablet in comparison to the that of unsintered tablets and pure drug was also observed, indicating the prolonged and controlled systemic availability of drug in biological system. The investigated sintered matrix tablets exhibited a remarkable increase in bioavailability due to prolonged plasma residence and could maintain constant plasma level of atenolol up to $24 \mathrm{hr}$ in rabbits.

Key words: In-vivo, Sintering, Pharmacokinetic Parameters, Controlled release, Matrix Tablet, Atenolol.

Copyright $\odot 2021$ The Author(s): This is an open-access article distributed under the terms of the Creative Commons Attribution 4.0 International License (CC BY-NC 4.0) which permits unrestricted use, distribution, and reproduction in any medium for non-commercial use provided the original author and source are credited.

\section{INTRODUCTION}

Atenolol (2-(4-\{2-hydroxy-3-[(propan-2-yl) amino] propoxy $\}$ phenyl) acetamide) is a selective $\beta 1$ receptor blocker, widely prescribed in hypertension, arrhythmias, angina pectoris, and myocardial infraction. Atenolol is included in class III category of BCS (biopharmaceutics classification system), that is high aqueous solubility and low gastrointestinal permeability [1]. The absorption of Atenolol after oral administration is rapid (peak plasma levels reaches in 2-4 hr) and consistent but incomplete [2]. Moreover, Atenolol has been reported to undergo extensive hepatic first-pass metabolism. Hence, oral bioavailability of Atenolol is only $50-60 \%$ and left behind being excreted unchanged in feces. In antihypertensive treatment, the oral dose of Atenolol is $50 \mathrm{mg}$ in conventional release system, twice a daily. But administration of conventional release tablets of Atenolol has been reported to exhibit fluctuations in plasma concentration of the drug, resulting either in adverse effects due to systemic accumulation of drug like nausea, ischemic colitis, diarrhoea and mesenteric thrombosis or decrease in concentration of drug at the receptor site. This combined with low oral bioavailability of atenolol make it suitable drug for the design of sustained release formulation to maintain a proper blood level of drug for a long time without fluctuation $[1,3]$.

The concept of sintering in pharmaceutical sciences is relatively new, but the research interests related to this process have been growing continuously. In powder metallurgy, sintering is defined as bonding of adjacent particle surfaces in a mass of powder or in compact, by the application of heat. Conventional sintering technique involves the heating of compact at a temperature below the melting point of the solid constituent in controlled environment under atmospheric pressure [4, 5]. In the pharmaceutical science, sintering has been described as the mechanism 
for the strengthening of the mechanical properties of consolidated pharmaceutical powder at elevated temperature, for solid-bond formation during tablet compression, and for thermal curing of polymer-latex film coating. The sintering process has been used for the fabrication of sustained- release matrix tablets for the stabilization the dug permeability of film coatings derived from various pharmaceutical lattices [6]. The sintering technique has been used for the fabrication of matrix tablet for sustained release and retardation of release of drug from various systems. The thermal sintering method involves fusion of polymer particles or formation of welded bond between particles by exposing the polymer matrix to the temperature above the glass transition temperature of the polymer. The entrapment of drug particles in the welded bond leads to controlled release of drug $[7,8]$.

Earlier we reported [9] the design polymeric matrix tablet of Atenolol using Eudragit RS 100 as sintering polymer and effect of sintering condition was evaluated. The aim of the present study was to assess the relative bioavailability i.e., rate and extent of absorption of formulated unsintered and sintered 100 mg polymeric matrix tablets of Atenolol with that of the pure Atenolol drug solution to study the effect of sintering technique in development of controlled release dosage form.

\section{MATERIALS AND METHODS Materials}

Atenolol and Eudragit RS 100 were obtained from Yarrow chemical products, Mumbai, India. Talc and Magnesium stearate were procured from Aurobindo Pharma Ltd, Hyderabad. All other chemicals and reagents used for the study were of analytical grade. Acetonitrile, potassium dihydrogen phosphate and dipotassium hydrogen phosphate were of HPLC grade, while all chemicals and other reagents used for the study were of analytical grade. Water used in this experiment was triple distilled and passed through 0.45micron filter paper with help of vacuum pump.

\section{Preparation of sintered matrix tablets of Atenolol for Pharmacokinetic Studies in rabbits}

Doses for rabbits were calculated based on BSA using the formula, Animal dose $(\mathrm{mg} / \mathrm{kg})=$ HED $(\mathrm{mg} / \mathrm{kg}) \times$ Conversion factor, where conversion factor for animal rabbit is 3.08 [10]. The matrix tablets were formulated by direct compression method with sintering polymer (Eudragit RS 100) and drug (Atenolol) at the ratio of 35:65; each tablet containing $13 \mathrm{mg}$ (at a dose level equivalent to $100 \mathrm{mg}$ of human dose) of Atenolol. Talc $(1 \% \mathrm{w} / \mathrm{w})$ and magnesium stearate $(0.5 \% \mathrm{w} / \mathrm{w})$ were added as glidant and lubricant respectively compressed into tablets using $3 \mathrm{~mm}$ punch. Sintering of tablets was done by using Hot air oven. The prepared matrix tablets were placed on aluminium foil and exposed to thermal treatment at $80^{\circ} \mathrm{C}$ for $3 \mathrm{hr}$ in hot air oven. The temperature of the oven was maintained within a degree Celsius. After the exposure to temperature and time the tablets were removed, cooled to room temperature and were stored in desiccators till further use.

\section{In-vivo pharmacokinetic studies}

Both unsintered and sintered controlled release matrix tablets of Atenolol were subjected to in vivo pharmacokinetic studies. Nine healthy male New Zealand rabbits ( 2.5 to $3 \mathrm{~kg}$ ) were used for these studies. The in vivo pharmacokinetic studies were performed with the permission of Institutional Animal Ethical Committee, Guru Nanak institutions technical campusSchool of pharmacy, Hyderabad, India (CPCSEA Registration Number: 1374/PO/Re/S/10/CPCSEA). The protocol for the animal experiment was approved by the IAEC (Approvalno.03/GNIP/CPCSEA/IAEC/2019). All the rabbits were fasted overnight with impromptu access to water on the penultimate day before the experimentation. These studies were performed by using parallel design. After an initial period of acclimatization for one week to laboratory conditions, rabbits were randomly divided into 3 groups with each group comprised of 3 rabbits. The first group received reference standard (Atenolol drug solution), second group was administered with unsintered matrix tablets of Atenolol and third group was administered with sintered matrix tablets of Atenolol. $13 \mathrm{mg}$ of pure Atenolol drug (plain drug) dissolved in distilled water was administered orally to the first group of rabbits through the oral tube. Few $\mathrm{ml}$ of distilled water was shoved through a syringe, (without needle) to ascertain that all the Atenolol reaches the stomach. The unsintered and sintered matrix tablet formulations containing $13 \mathrm{mg}$ of Atenolol were administered orally at the end of the throat to the second and third groups of rabbits respectively by using an oral tube. After receiving the oral dose, immediately $10 \mathrm{ml}$ of distilled water was administered through the tube to facilitate the accession of the tablets and to stop it from protruding to the rabbit's throat. Animal were accessed to food after 4 $\mathrm{h}$ of administration of dose. Blood samples $(1.0 \mathrm{ml})$ were collected from marginal ear vein at time intervals of 0 (pre-dose), 1, 2, 3, 4, 6, 8, 10, 12, 14, 18 and $24 \mathrm{hr}$ after administration, into heparinized eppendorf tubes. Plasma was separated by centrifugation of blood at $5000 \mathrm{rpm}$ for $5 \mathrm{~min}$ and stored in a freezer until the samples were analyzed.

\section{Instrumentation and chromatographic conditions}

The HPLC system consisted of a UV-Vis detector (Shimadzu, Model: SPD-10 A), Inertsil ODS C-18 column $(4.6 \times 250 \mathrm{~mm}$, particle size $5 \mu \mathrm{m})$. The mobile phase was composed of phosphate buffer, $\mathrm{pH}$ 3.0: and acetonitrile (50:50 v/v). Both acetonitrile and phosphate buffer solution were filtered before use through $0.45-\mu \mathrm{m}$ membrane filter, was run at a flow rate of $1.2 \mathrm{ml} / \mathrm{min}$. The injection volume was about 
$50 \mu \mathrm{l}$ and the run time was fixed for $20 \mathrm{~min}$. The HPLC system and the column were kept in ambient temperature and the eluents were monitored at $230 \mathrm{~nm}$ $[11,12]$.

\section{Preparation of standard stock solutions}

Stock solutions of atenolol and its internal standard procainamide, each $100 \mu \mathrm{g} / \mathrm{ml}$ were prepared in water. Daily working standard solutions of drug (Atenolol) and IS (Procainamide) were prepared by suitable dilution of the stock solution with the mobile phase.

\section{Sample preparation}

An aliquot of plasma $(0.5 \mathrm{~mL})$ sample was transferred to a $10-\mathrm{mL}$ glass tube. A $50 \mu \mathrm{L}$ of standard atenolol solutions were added, together with the $25 \mu \mathrm{L}$ of the IS procainamide solution and $25 \mu \mathrm{L}$ of $10 \mathrm{M}$ $\mathrm{NaOH}$ solution. After vortex mixing for $30 \mathrm{~s}, 3 \mathrm{~mL}$ of n-butanol-n-hexane (1:1) was added as extracting solvent; the mixture was vortexed for $30 \mathrm{~s}$ and then centrifuged at 3,000 rpm for $5 \mathrm{~min}$. The upper organic layer was transferred into another $10-\mathrm{mL}$ tube and after the addition of $1 \mathrm{~mL}$ of acetonitrile; the mixture was vortexed for $30 \mathrm{~s}$ and then was centrifuged at 3,000 rpm for $30 \mathrm{~s}$. After separating the upper organic phase, the lower aqueous phase was transferred into the injection vial and a fifty microliters aliquot was injected into the HPLC system [13].

\section{Preparation of calibration solutions}

Calibration standard sample solutions were freshly prepared in $0.5 \mathrm{~mL}$ of rabbit plasma by spiking with $50 \mu \mathrm{L}$ of the atenolol working solutions and $25 \mu \mathrm{L}$ of the internal standard working solution to yield final concentration of atenolol equivalent to 10 , $25,50,100,250,500$ and $1,000 \mathrm{ng} / \mathrm{mL}$ of atenolol along with $1.25 \mu \mathrm{g} / \mathrm{ml}$ of internal standard procainamide. The samples were extracted as described before.

\section{In Vivo Data Analysis}

The pharmacokinetic parameters, namely, maximum plasma concentration $\left(\mathrm{C}_{\max }\right)$ and time to reach maximum plasma concentration $\left(\mathrm{T}_{\max }\right)$ were obtained directly from the observed values. The AUC (area under the plasma concentration-time curve) from the time of administration to the last observed concentration at time ' $\mathrm{t}$ ' $\left(\mathrm{AUC}_{0-\mathrm{t}}\right)$ was calculated by the trapezoidal rule from the observed values. The value of overall elimination rate constant $\left(\mathrm{K}_{\mathrm{E}}\right)$ was calculated using the least-squares regression analysis of the terminal portion of the log plasma concentration vs time curve. The AUC of the plasma concentration-time curve extrapolated to infinitive time $\left(\mathrm{AUC}_{0-\infty}\right)$ was calculated by dividing the last measurable plasma drug concentration with the elimination rate constant $\left(\mathrm{K}_{\mathrm{E}}\right)$ and adding the result to the $\mathrm{AUC}_{0-\mathrm{t}}$. The Elimination half -life (T1/2) was calculated by dividing 0.693 with $\mathrm{K}_{\mathrm{E}}[14]$.

\section{RESULT AND DISCUSSION}

The HPLC chromatograms and retention times of Blank plasma, plasma spiked with Atenolol and Procainamide are shown in figures 1-2. Satisfactory sharp peaks of the drug and IS, markedly resolved with widened separations were observed. It was also observed that blank plasma has no endogenous interference with analyte atenolol or internal standard. Drug (Atenolol) and IS (Procainamide) appeared on the chromatogram in 2.054 and 6.119 min respectively with no interfering peaks.

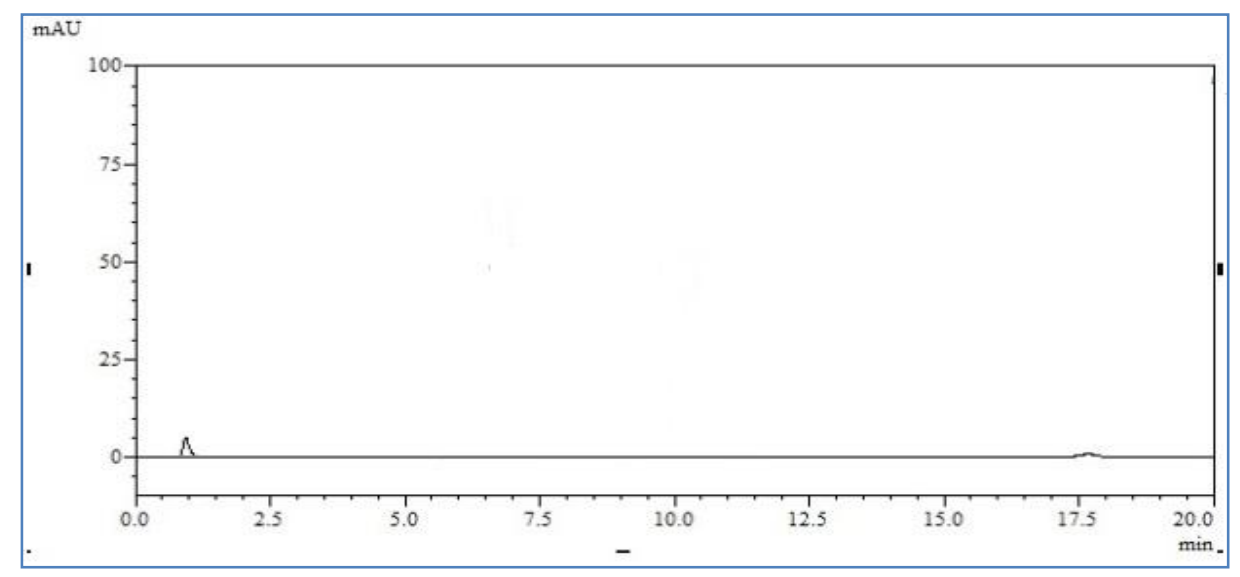

Fig-1: Chromatogram of Blank plasma 


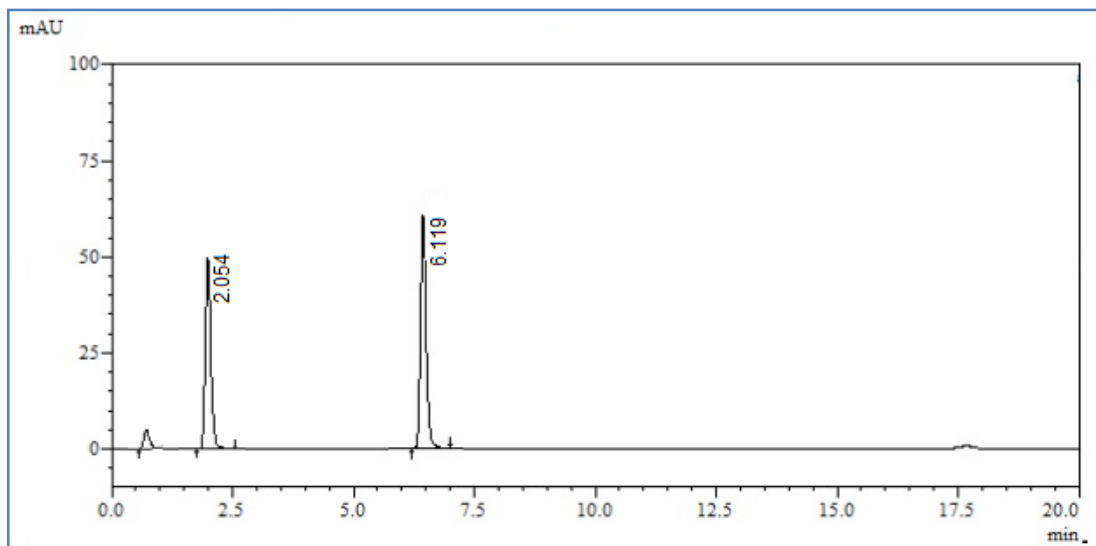

Fig-2: Chromatogram of rabbit plasma spiked with analyte Atenolol (Rt-2.054 min) \& Internal Standard Procainamide (Rt6.119 min)

The standard calibration curve of Atenolol in rabbit plasma was constructed by plotting the relative peak area ratios of atenolol and IS on the Y-axis and the respective concentrations of atenolol on the $\mathrm{X}$-axis. The calibration curve demonstrated linearity over the range of $10-1000 \mathrm{ng} / \mathrm{ml}$. The linearity of results was depicted Figure.3.

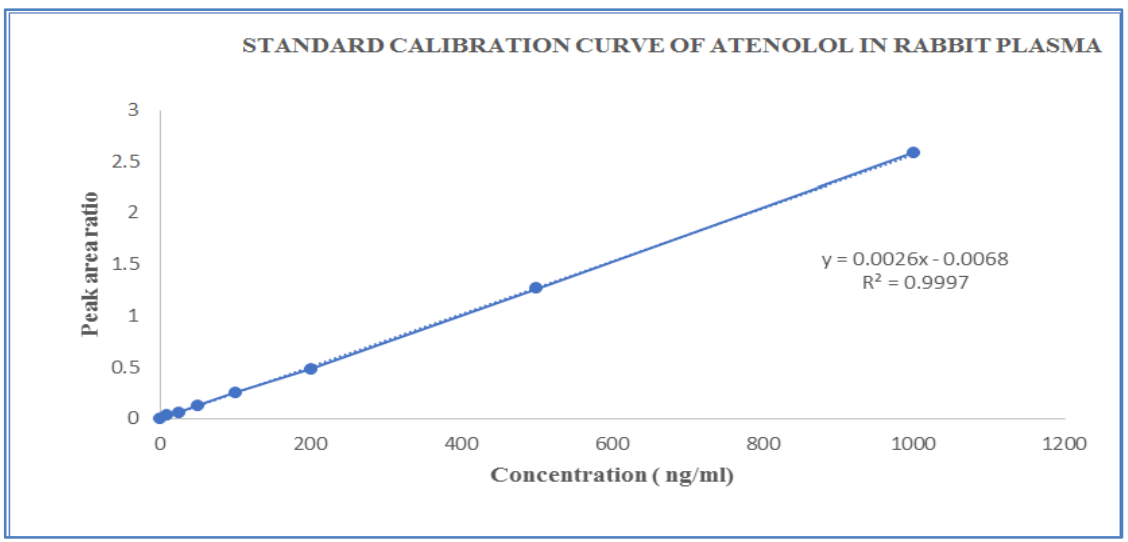

Fig-3: Standard calibration curve of Atenolol with Procainamide as internal standard in rabbit plasma

The regression equation was found to be $Y=0.0026 \mathrm{X}+0.0068$ with a regression coefficient of 0.9997 , where ' $\mathrm{Y}$ ' is the peak area ratio and ' $\mathrm{X}$ ' is the concentration of Atenolol in rabbit plasma. This equation was used to estimate the amount of atenolol in plasma.
Comparative plasma atenolol drug concentration profile after oral administration of a 13 mg pure Atenolol drug, both formulated unsintered and sintered controlled release matrix tablets of Atenolol to 3 groups of 3 healthy rabbits are shown in Tables 1 and Figure 4.

Table-1: In vivo pharmacokinetic parameters of pure drug Atenolol and its formulated unsintered \& sintered matrix tablets in Rabbits

\begin{tabular}{|l|l|l|l|}
\hline $\begin{array}{l}\text { pharmacokinetic } \\
\text { parameters }\end{array}$ & $\begin{array}{l}\text { Atenolol pure } \\
\text { drug }\end{array}$ & $\begin{array}{l}\text { Formulated unsintered matrix } \\
\text { tablets of Atenolol }\end{array}$ & $\begin{array}{l}\text { Formulated sintered matrix } \\
\text { tablets of Atenolol }\end{array}$ \\
\hline $\mathrm{C}_{\text {max }}(\mathrm{ng} / \mathrm{mL})$ & $751.00 \pm 10.53$ & $639.33 \pm 10.40$ & $518.00 \pm 8.54$ \\
\hline $\mathrm{T}_{\max }(\mathrm{hr})$ & $2 \mathrm{hr}$ & $3 \mathrm{hrs}$ & $4 \mathrm{hrs}$ \\
\hline $\mathrm{K}_{\mathrm{E}}\left(\mathrm{hr}^{-1}\right)$ & 0.223 & 0.166 & 0.110 \\
\hline $\mathrm{T}_{1 / 2}(\mathrm{hr})$ & 3.10 & 4.17 & 6.30 \\
\hline $\mathrm{AUC}_{0-\mathrm{t}}(\mathrm{h} . \mathrm{ng} / \mathrm{mL})$ & 2634.33 & 3423.50 & 4286.66 \\
\hline $\mathrm{AUC}_{0-\infty}(\mathrm{h} . \mathrm{ng} / \mathrm{mL})$ & 2735.94 & 3614.22 & 4619.93 \\
\hline
\end{tabular}




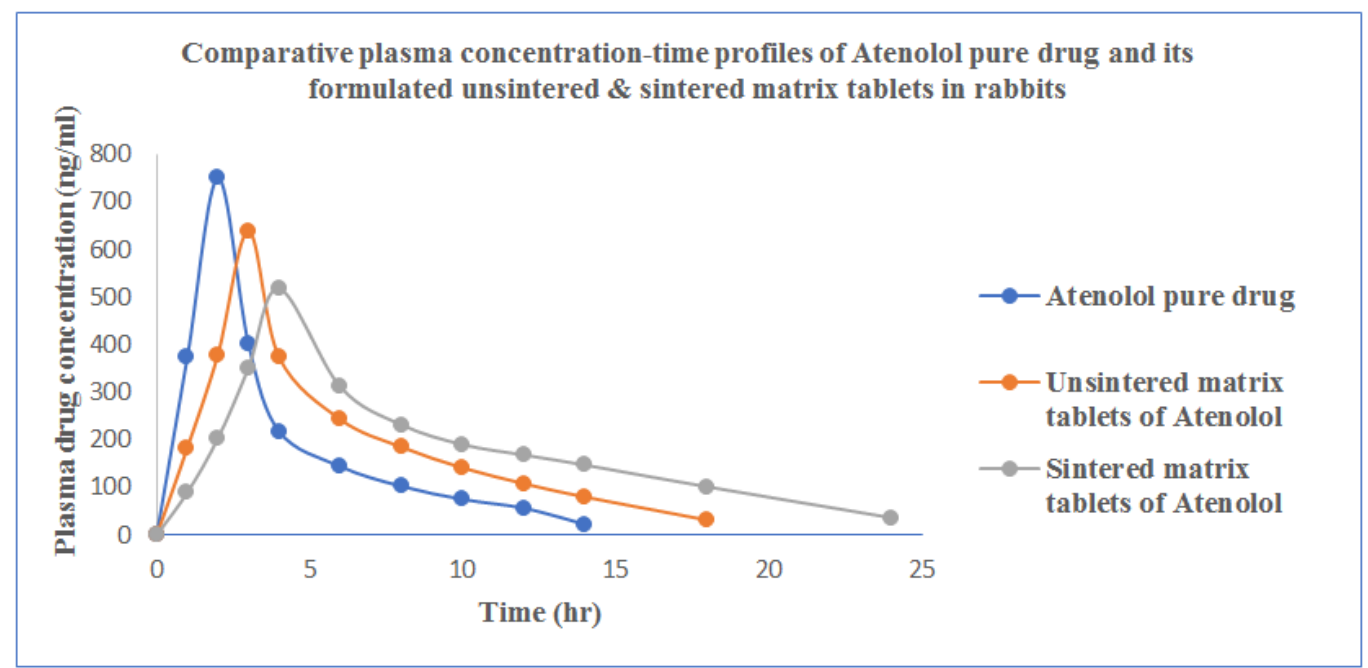

Fig-4: Comparative plasma concentration-time profiles of Atenolol pure drug and its formulated unsintered \& sintered matrix tablets in Rabbits

The results showed that Atenolol administered as plain drug alone reached peak plasma concentration $\left(\mathrm{C}_{\max }\right)$ of $751.00 \pm 10.53 \mathrm{ng} / \mathrm{ml}$ after $2 \mathrm{hr}$ of administration. Whereas the $\mathrm{C}_{\max }$ of $639.33 \pm 10.40$ $\mathrm{ng} / \mathrm{ml}$ at $3.0 \mathrm{~h}$ and $\mathrm{C}_{\max }$ of $518.00 \pm 8.54 \mathrm{ng} / \mathrm{ml}$ at $4.0 \mathrm{~h}$ were observed after oral administration of unsintered and sintered matrix tablets, respectively. Cmax of the prepared matrix tablets was found to be comparatively less to that of pure drug solution.

Atenolol drug slution was found to be rapidly absorbed as $\mathrm{T}_{\max }$ was reached in about $2 \mathrm{hr}$ and for unsintered tablets it was relatively more $\left(\mathrm{T}_{\max }\right.$ in $3 \mathrm{hr}$ ), whereas in case of sintered tablets the $T_{\max }$ had achieved very slowly ( $\mathrm{T}_{\max }$ in $4 \mathrm{hr}$ ) and the drug availability was found to be prolonged. Increase in $T_{\max }$ value of sintered tablets is the indication the availability of drug at a controlled manner.

The elimination constant $\left(\mathrm{K}_{\mathrm{E}}\right)$ for Atenolol in the prepared sintered matrix tablet was found to be $0.110 / \mathrm{hr}$, while for unsintered tablets and pure drug it was found to be $0.166 / \mathrm{hr}$ and $0.223 / \mathrm{hr}$ respectively. Based on the elimination constant values, the biological half-life was calculated and was found to be $6.30 \mathrm{~h}$ for the sintered tablet $4.17 \mathrm{hr}$ for unsintered tablets and $3.10 \mathrm{~h}$ for the pure drug solution.

An increase of the half-life and decrease in elimination rate constant of drug in sintered matrix tablet in comparison to the that of unsintered tablets and pure drug, indicates the increased residence time, prolonged and controlled systemic availability of drug in biological system.

The $\mathrm{AUC}_{0-\mathrm{t}}$ of pure Atenolol drug solution and unsintered tablet was found to be $2634.33 \mathrm{~h} . \mathrm{ng} / \mathrm{mL}$ and 3423.50 h.ng/mL respectively. $\mathrm{AUC}_{0-\mathrm{t}}$ in sintered formulation was found to be increased to around
4286.66 h.ng/mL, which clearly suggests the enhanced in-vivo drug availability.

As evident from the pharmacokinetic parameters, the sintered matrix tablets of Atenolol showed prolonged release and were able to release the drug effectively at a rate-controlled manner for a prolonged period of time up to $24 \mathrm{hrs}$.

\section{CONCLUSION}

A new controlled release sintered matrix tablets of Atenolol has been developed and evaluated for its in vivo drug release. The investigated sintered matrix tablets were capable of maintaining constant plasma level of atenolol up to $24 \mathrm{~h}$ in rabbits. The sintering condition markedly affected the in vivo drug absorption characteristics from the sintered tablets. The sintered matrix tablets showed a distinguished increase in bioavailability due to prolonged plasma residence of the drug. Formulated product prepared with sintering technique displayed prolonged release with reduce plasma drug fluctuations in comparison to the pure drug and formulated product prepared without using Sintering Technique. Thus, from the results of the present study, we may conclude that simple technique of thermal sintering may be used in the design of matrix tablets of Atenolol to reduce dosing frequency, doserelated adverse effects and the dose intake, to minimize the fluctuations in plasma drug concentration and ultimately improve the patient compliance in the drug therapy management.

\section{ACKNOWLEDGEMENT}

The authors wish to acknowledge Guru Nanak Institutions Technical Campus-School of pharmacy, Hyderabad, India, authority and Remedium laboratories, Hyderabad, India for providing research laboratory and instrumental facilities to carry out this work. 


\section{REFERENCES}

1. Bianca Ramos Pezzini , Amanda Daniela Grossl, Amanda Muraro, Melissa Zétola, Giovana Carolina Bazzo and Luciano Soares; Formulation and in vitro assessment of sustained release matrix tablet of Atenolol containing kollidon SR and carnauba wax; African journal of pharmacy and pharmacology. 2014; 8(41), 1058-1065.

2. Ahmed A. Hussein. Determination of Atenolol in Human Plasma by New HPLC Method with Fluorescence Detection for Pharmacokinetics Studies. Kerbala Journal of Pharmaceutical Sciences. 2014, 4: 238-261.

3. Manas Bhowmik, Oindrila Baisya, Jyotirmoy Deb; Formulation and evaluation of sustained release matrix tablet of Atenolol based on natural polymer; Research journal of pharmaceutical, biological and chemical sciences. 2012, 13(4), 878-886.

4. Luk CL and Jane HL. Encyclopedia of pharmaceutical technology. In: J. Swarbrick and J. C. Boylans, editors. Sintering in pharmaceutics. Second edition. New York. Marcel Dekker. 1996; 87-101.

5. Tejaswini s Pawatekar, Ramdas B. Rode. A review on sintering method in Pharmaceutical sciences. Asian J. Pharm. Tech. 2014; 4(2): 106-109.

6. Chandan Mohanty. Sintering technique in pharmaceutical sciences: a brief review. International journal of pharmatech. 2011; 3(1): 799-806.

7. Chandan Mohanty, K V Subrahmanyam, Tapan k Jena, D Sreekanth. Use of Sintering Technique to Sustain the Release of Atazanavir Sulphate from Gastro Retentive Floating Matrix Tablets. American journal of Pharmatech and Research. 2015; 5(4); 587-607.
8. Chandan Mohanty, K V Subrahmanyam, Abdul Saleem Mohammad, Tapan Kumar Jena. Thermal sintering technique: a novel strategy used in the design of gastro retentive floating matrix tablets nicardipine HL and its evaluation. International Journal of pharma Research and Health Sciences. 2016; 4(1): 1004-1009.

9. Chandan Mohanty, KV Subrahmanyam. Effect of sintering condition on Physico-chemical parameters and drug release characteristics from polymeric matrix tablet of Atenolol for controlled release. International journal of pharmaceutical sciences and research. 2017; 8(9): 1000-1009.

10. Chang-Gue Son, Jang-Woo Shin, In-Chan Seol. Interpretation of animal dose and human equivalent dose for drug Development. The Journal of Korean Oriental Medicine. 2010; 31(3): 1-7.

11. Naveen Kumar, Nishant Verma, Omveer Songh, Naveen Joshi, Kanwar Gaurav Singh. Estimation of atenolol by reverse phase high performance liquid chromatography. E-Journal of Chemistry. 2010; 7(3): 962-966.

12. Ravi Sankar P, Madhuri B, Naga Lakshmi A, Pooja A, Bhargava Sai M, Suresh K, and Srinivasa Babu P; Selected HPLC Applications-Quick Separation Guide: A Review. International Journal of Pharmaceutical Sciences Review and Research. 2020; 3: 13-20.

13. Marios Spanakis, Ioannis Niopas. Determination of Atenolol in Human Plasma by HPLC with Fluorescence Detection: Validation and Application in a Pharmacokinetic Study. Journal of Chromatographic Science. 2013; 51:128-132

14. Bilal Yilmaz1, Sakir Arslan, Ali Asci. HPLC Method for Determination of Atenolol in Human Plasma and Application to a Pharmacokinetic Study in Turkey. Journal of Chromatographic Science. 2012; 50, 914-919. 